\title{
Presence of Multiple Mycotoxins and Other Fungal Metabolites in Native Grasses from a Wetland Ecosystem in Argentina Intended for Grazing Cattle
}

\author{
María J. Nichea ${ }^{1}$, Sofia A. Palacios ${ }^{1}$, Stella M. Chiacchiera ${ }^{2}$, Michael Sulyok ${ }^{3}$, Rudolf Krska ${ }^{3}$, \\ Sofia N. Chulze ${ }^{1}$, Adriana M. Torres ${ }^{1}$ and María L. Ramirez ${ }^{1, *}$
}

1 Departamento de Microbiología e Inmunología, Facultad de Ciencias Exactas Fco-Qcas y Naturales, Universidad Nacional de Río Cuarto, Ruta 36 Km 601, Río Cuarto 5800, Córdoba, Argentina; E-Mails: mnichea@exa.unrc.edu.ar (M.J.N.); spalacios@exa.unrc.edu.ar (S.A.P.); schulze@exa.unrc.edu.ar (S.N.C.); atorres@exa.unrc.edu.ar (A.M.T.)

2 Departamento de Química, Facultad de Ciencias Exactas Fco-Qcas y Naturales, Universidad Nacional de Rio Cuarto, Ruta 36 Km 601, Río Cuarto 5800, Córdoba, Argentina; E-Mail: schiacchiera@exa.unrc.edu.ar

3 Department IFA-Tulln, BOKU Vienna, Konrad Lorenzstr 20, Tulln A-3430, Austria; E-Mails: michael.sulyok@boku.ac.at (M.S.); rudolf.krska@boku.ac.at (R.K.)

* Author to whom correspondence should be addressed; E-Mail: mramirez@exa.unrc.edu.ar; Tel.: +54-358-467-6429; Fax: +54-358-467-6231.

Academic Editor: Paola Battilani

Received: 27 June 2015 / Accepted: 14 August 2015 / Published: 20 August 2015

\begin{abstract}
The aim of this study was to evaluate the occurrence of several fungal metabolites, including mycotoxins in natural grasses (Poaceae) intended for grazing cattle. A total number of 72 and 77 different metabolites were detected on 106 and 69 grass samples collected during 2011 and 2014, respectively. A total of 60 metabolites were found across both years. Among the few mycotoxins considered toxic for ruminants, no samples of natural grasses were contaminated with aflatoxins, ochratoxin A, ergot alkaloids, and gliotoxin, among others. However, we were able to detect important metabolites (toxic to ruminants) such as type A trichothecenes, mainly T-2 toxin and HT-2 toxin (up to $5000 \mu \mathrm{g} / \mathrm{kg}$ each), and zearalenone (up to $2000 \mu \mathrm{g} / \mathrm{kg}$ ), all at very high frequencies and levels. Other fungal metabolites that were found to be prevalent were other Fusarium metabolites like beauvericin, equisetin and aurofusarin, metabolites produced by Alternaria spp., sterigmatocystin and its precursors and anthrachinone derivatives. It is
\end{abstract}


important to point out that the profile of common metabolites was shared during both years of sampling, and also that the occurrence of important metabolites is not a sporadic event. Considering that this area of temperate grassland is used for grazing cattle all year long due to the richness in palatable grasses (Poaceae), the present work represents a starting point for further studies on the occurrence of multi-mycotoxins in natural grasses in order to have a complete picture of the extent of cattle exposure. Also, the present study shows that the presence of zeranol in urine of beef cattle may not be a consequence of illegal use of this banned substance, but the product of the natural occurrence of zearalenone and $\alpha$-zearalenol in natural grasses intended for cattle feeding.

Keywords: Poaceae; grasses; mycotoxins; Fusarium; cattle feed; bacterial and fungal metabolites

\section{Introduction}

Extensive beef production is a distinctive feature of Argentina. Beef production is generally based on grazing native grasses and cultivated pastures [1]. Nearly all the cattle are raised through grazing, with only $1.2 \%$ finished in corrals. Grazing throughout the year produces leaner beef cuts with less cholesterol and greater polyunsaturated fatty acids than beef finished on a high grain diet in feedlot [2]. Conventional cattle grazing in Argentina provides a desirable product for internal and external markets [3]. The prospects for Argentinean beef exports are promising, mainly due to the country's recent advancements in sanitary status. Argentina has been declared free of foot and mouth disease with vaccination, and also has been assigned the best possible status for a low Bovine Spongiform Encephalopathy (BSE) risk. These achievements, together with the fertile soil and climate characteristics for beef production, are driving forces for the increase in the country's beef exports [1].

Mycotoxins are naturally occurring compounds or secondary metabolites produced by fungi growing on plants in the field or during storage. Mycotoxins can contaminate raw agricultural products before and/or after harvest. Numerous mycotoxins can be produced by fungi invading plant material; however, only few mycotoxins have been recognized as toxic to ruminants. Mycotoxins relevant for ruminant's health are aflatoxins, ochratoxin $\mathrm{A}$, zearalenone, fumonisins ( $\mathrm{B}_{1}$ and $\left.\mathrm{B}_{2}\right)$, trichothecenes, ergot alkaloids, and gliotoxin among others [4].

The negative effect of mycotoxins on the growth and health of livestock makes them a major problem for many production systems. Mycotoxicosis symptoms depend on the type of mycotoxin, the amount and duration of the exposure, the age, health and sex of the exposed individual, as well as on the dietary status and interactions among toxins. Low levels of mycotoxins may cause reduction decrease in food intake and performance, such as lowered milk production or decrease in body weight gain. Moderate levels of feed contamination frequently result in impaired resistance to infections, increased susceptibility to stress and reduced fertility. High levels of contamination may produce clinical disease, liver and kidney damage, oedema, increased blood clotting time and haemorrhaging, as well as altered digestion, absorption and metabolism of nutrients. Ruminants are less sensitive to the 
negative mycotoxin effects since rumen microbiota can effectively degrade and deactivate mycotoxins, hence protecting the animal $[5,6]$.

Beef animals in Argentina are finished either solely on natural grasses or pastures, on pastures with supplemented feeding (in most cases corn or sorghum silage) or in feedlots [7]. In Argentina, several reports showed mycotoxin contamination in cattle feed ingredients such as corn grains, mixed rations (corn, protein concentrate, etc.), corn silage, soybean pellet, wheat bran, etc. all used in feedlot rearing practice [8]. However, there is little information on the natural occurrence of mycotoxins in natural grasses (uncultivated) devoted to cattle grazing.

Of particular concern to the Argentinean livestock industry is that zearalenone is chemically similar to the growth promoting $\alpha$-zearalanol (zeranol), which is banned in Argentina as well as in the EU. In the last five years, zeranol has been detected in bovine urine during the routine analysis of beef cattle farms (enrolled as EU exporter) as part of a national residue control plan by the central governing authority, the National Service for Health and Food Quality (SENASA). It is important to remark that on those cattle farms, the cattle were raised through grazing of natural grasses, without any external inputs. The present research was primarily undertaken to ascertain if zearalenone was present in natural grasses on two beef cattle farms, in which a positive urine sample for zeranol from cattle had been previously found. It is well known that zeranol can be formed from $\alpha$-zearalenol and zearalenone in vivo in cattle [9]. Several reports from New Zealand and Northern Ireland have shown that zeranol might occur naturally in urine and bile from sheep and cattle, following metabolism of the mycotoxins zearalenone and $\alpha$-zearalenol that can contaminate animal feedstuffs $[9,10]$. Thus, the finding of zeranol in an animal might, on its own, be insufficient proof that malicious abuse of zeranol has occurred. As natural grasses (Poaceae) were the unique feed source for the cattle raising in the aforementioned cattle farming, we wanted to probe for the first time in Argentina that natural grasses were contaminated with zearalenone and that it was the possible source of zeranol. The two farms in this study were located at a Ramsar Wetland site $\left(27^{\circ} 20^{\prime} \mathrm{S} 58^{\circ} 50^{\prime} \mathrm{W}\right.$, Ramsar site No. 1366) in Chaco province, Argentina [11]. This wetland ecosystem is one of the three most biodiverse biomes of Argentina and it covers part of the Parana and Paraguay rivers floodplain complex at the eastern border of Chaco Province. The landscape consists of complex open water, aquatic vegetation, grasslands and gallery forests. This temperate grassland is used for grazing cattle all year long due to the richness of palatable grasses (Poaceae).

Based on what has been mentioned above, the aims of this study were to evaluate the occurrence of several fungal metabolites including mycotoxins in natural grasses intended for cattle grazing and to determine the co-occurrence of toxins that may be relevant to impairing cattle growth and health.

\section{Results}

\subsection{Performance of the Applied Analytical Method}

The performance characteristics of the analytical method obtained from five spiked blank samples are presented in Table 1 (only those analytes that have later been detected in the survey are shown). The limits of detection (LOD) ranged between 0.03 (averufin and festuclavine) and $20 \mu \mathrm{g} / \mathrm{kg}$ (kojic acid). 
Spiking experiments using five individual samples at two concentration levels revealed that the apparent recoveries are in general lower than those obtained with other (grain-based) matrices [12,13].

Table 1. Performance characteristics of the analytical method for all analytes detected in the investigated grass samples.

\begin{tabular}{|c|c|c|}
\hline Analyte & Apparent Recovery (\%) & $\operatorname{LOD}^{\text {a }}(\mu \mathrm{g} / \mathrm{kg})$ \\
\hline 3-Nitropropionic acid & $63.3 \pm 9.5$ & 0.40 \\
\hline Agroclavine & $59.5 \pm 5.1$ & 0.08 \\
\hline Altenuene & $157.8 \pm 40.0$ & 2.00 \\
\hline Alternariol & $100.0 \pm 9.5$ & 0.50 \\
\hline Alternariol methyl ether & $96.6 \pm 8.8$ & 0.05 \\
\hline Altertoxin-I & $77.9 \pm 6.5$ & 0.80 \\
\hline Aspinolid B & $75.5 \pm 13.2$ & 0.80 \\
\hline Asterric acid & $140.0 \pm 9.6$ & 3.00 \\
\hline Aurofusarin & $75.3 \pm 4.7$ & 4.00 \\
\hline Averantin & $76.5 \pm 0.9$ & 0.04 \\
\hline Averufanin ${ }^{b}$ & n.d. ${ }^{d}$ & - \\
\hline Averufin & $54.50 \pm 2.50$ & 0.03 \\
\hline Beauvericin & $41.8 \pm 6.0$ & 0.04 \\
\hline Brefeldin A & $66.5 \pm 6.2$ & 2.00 \\
\hline Brevianamid $\mathrm{F}$ & $76.2 \pm 2.1$ & 0.40 \\
\hline Chanoclavin & $73.5 \pm 31.2$ & 0.05 \\
\hline Chrysophanol & $114.8 \pm 11.8$ & 1.50 \\
\hline Clonostachydiol & $80.0 \pm 21.0$ & 0.80 \\
\hline Curvularin & $127.6 \pm 15.8$ & 0.40 \\
\hline Cytochalasin B & $66.8 \pm 7.1$ & 1.50 \\
\hline Cytochalasin C & $66.8 \pm 6.1$ & 0.40 \\
\hline Cytochalasin D & $62.5 \pm 4.1$ & 0.20 \\
\hline Cytochalasin $\mathrm{H}$ & $57.2 \pm 5.6$ & 15.00 \\
\hline Cytochalasin J & $59.2 \pm 7.9$ & 2.00 \\
\hline Dechlorogriseofulvin & $73.7 \pm 9.1$ & 1.50 \\
\hline Diacetoxyscirpenol & $61.0 \pm 9.8$ & 0.25 \\
\hline Dihydrogriseofulvin & $69.7 \pm 8.8$ & 1.00 \\
\hline Emodin & $131.3 \pm 28.2$ & 0.08 \\
\hline Enniatin B & $77.7 \pm 42.9$ & 0.01 \\
\hline Equisetin & $215.0 \pm 38.7$ & 0.08 \\
\hline Festuclavine & $73.1 \pm 17.3$ & 0.03 \\
\hline Fumonisin $\mathrm{B}_{1}$ & $59.8 \pm 8.1$ & 3.00 \\
\hline Griseofulvin & $69.7 \pm 4.8$ & 0.80 \\
\hline HT-2 toxin & $68.3 \pm 1.0$ & 4.00 \\
\hline Kojic acid & $83.4 \pm 12.2$ & 20.00 \\
\hline Macrosporin & $125.8 \pm 5.2$ & 0.20 \\
\hline Moniliformin & $113.7 \pm 6.7$ & 1.00 \\
\hline Monocerin & $73.8 \pm 3.0$ & 0.40 \\
\hline Neosolaniol & $79.2 \pm 3.5$ & 0.50 \\
\hline Nidurufin ${ }^{\mathrm{b}}$ & n.d. & - \\
\hline
\end{tabular}


Table 1. Cont.

\begin{tabular}{ccc}
\hline Analyte & Apparent Recovery $(\%)$ & LOD $^{\text {a }}(\boldsymbol{\mu g} / \mathbf{k g})$ \\
\hline Nivalenol & $41.3 \pm 12.0$ & 0.80 \\
Norsolorinic acid & $47.0 \pm 15.1$ & 0.40 \\
Penicillide & $110.9 \pm 16.3$ & 1.50 \\
Physcion & $114.3 \pm 16.6$ & 8.00 \\
Pseurotin A & $73.7 \pm 48.7$ & 0.50 \\
Radicicol & $117.0 \pm 12.0$ & 0.40 \\
Secalonic acid D & $79.1 \pm 8.6$ & 4.00 \\
Skyrin & $76.1 \pm 4.6$ & 0.20 \\
Sterigmatocystin & $69.6 \pm 4.0$ & 0.30 \\
Sulochrin & $89.7 \pm 14.9$ & 1.50 \\
T-2 toxin & $64.1 \pm 3.6$ & 0.80 \\
Tentoxin & $56.2 \pm 11.9$ & 0.20 \\
Tenuazonic acid & $407.4 \pm 108.9$ & 3.00 \\
Tryptophol & $79.7 \pm 6.4$ & 15.0 \\
Versicolorin A & $103.7 \pm 3.6$ & 0.40 \\
Versicolorin C & n.d. & - \\
Zearalenone & $124.6 \pm 10.9$ & 0.30 \\
Zearalenone-4-sulfate $^{\mathrm{c}}$ & $143.1 \pm 16.1$ & 0.40 \\
$\alpha$-zearalenol & $120.6 \pm 17.2$ & 0.80 \\
$\beta$-zearalenol & $109.3 \pm 15.6$ & 0.80 \\
\hline
\end{tabular}

${ }^{a}$ LOD, limit of detection; ${ }^{b}$ No standard available, estimation of concentration based on response and recovery of averufin; ${ }^{\mathrm{c}}$ No standard available, estimation of concentration based on response and recovery of versicolorin $\mathrm{A} ;{ }^{\mathrm{d}}$ n.d.: not determined.

\subsection{Occurrence of Fungal Metabolites in Natural Grass Samples}

A total number of 72 and 77 different metabolites were detected on grass samples collected during 2011 and 2014 years, respectively. A total of 60 metabolites were shared on both years evaluated. Data on shared mycotoxin prevalence between both sampling years as well as related median and maximum concentration in the positive samples are compiled in Table 2. The list of the most prevalent metabolites was similar between both years; despite this, there was a lower prevalence/or lower concentration in the grass samples from 2014. It was noticeable that, all the non-shared metabolites found in a particular year were detected in very few samples, these being unimportant metabolites in terms of toxicity for ruminants (Data not shown). The only exception was the presence of deoxynivalenol in grass samples collected during 2011. As an example, Figure 1 shows contamination levels of 16 Fusarium mycotoxins detected in both years of sampling (except deoxynivalenol), and significant differences $(p<0.05)$ were found in the levels between both years in deoxynivelenol, beauvericin, enniantin B and equisetin, which appeared to be lower during 2014 in comparison with those collected during 2011.

In respect to Fusarium mycotoxins present in natural grass samples during both years evaluated, it was observed that during 2011, beauvericin and equisetin were present in all the samples and monocerin, zearalenone and aurofusariun were present in $\geq 90 \%$ of the samples. Other Fusarium mycotoxins detected at a prevalence of $40 \%-70 \%$ were HT-2 toxin, $\alpha$-zearalenol, zearalenone- 4 
sulfate, T-2 toxin and enniantin B. Neosolaniol, $\beta$-zearalenol, nivalenol, moniliformin and fumonisin $\mathrm{B}_{1}$ were detected at frequencies of $36 \%, 28 \%, 15 \%, 12 \%$ and $11 \%$, respectively. Deoxynivalenol, enniantin $\mathrm{A}$ and $\mathrm{A}_{1}$, culmorin and diacetoxyscirpenol were found in low abundance $\leq 10 \%$.

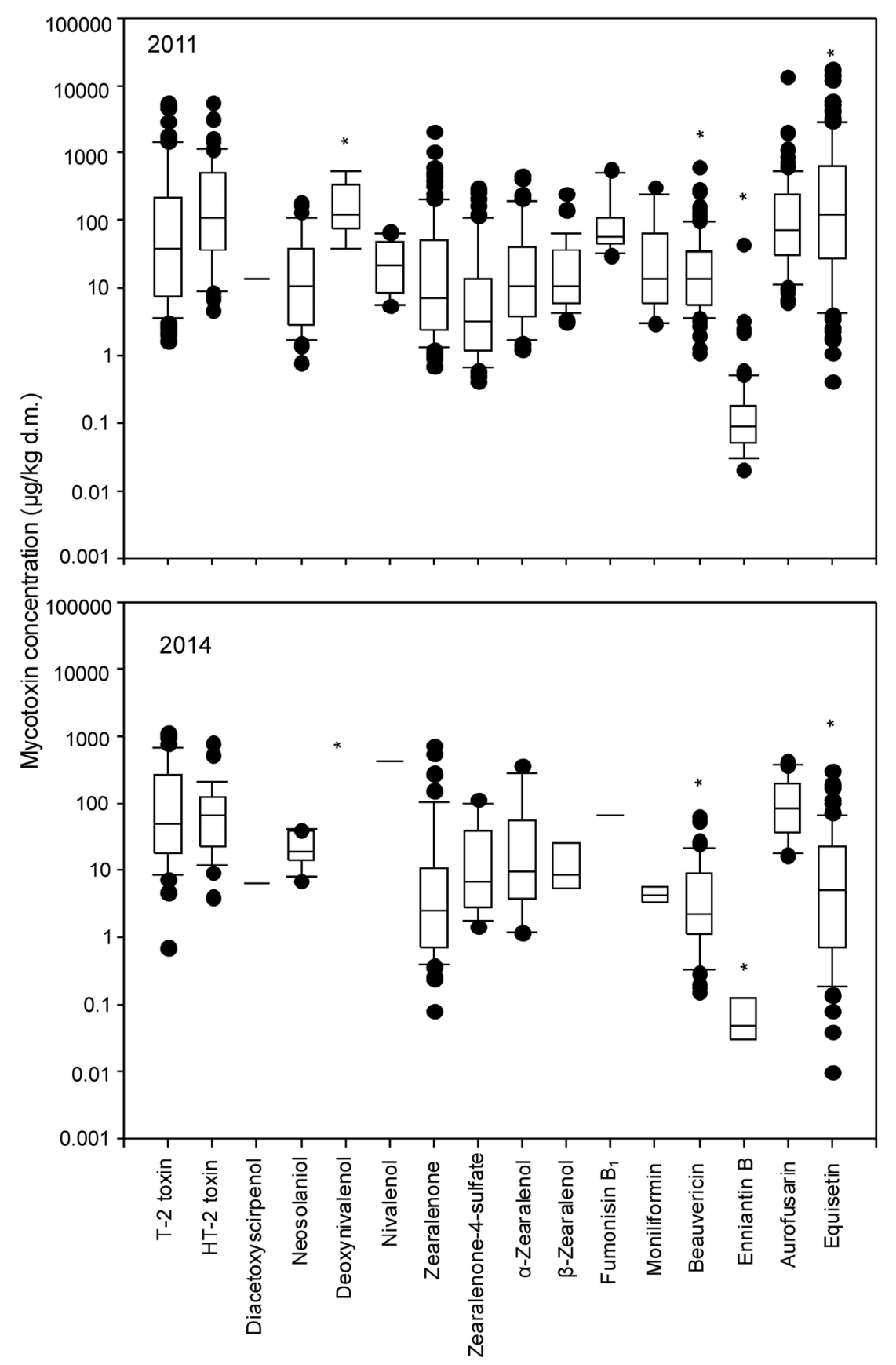

Figure 1. Box-plot for Fusarium mycotoxin concentration in grass samples during both years of study. (* for a particular toxin denotes significant differences between both years evaluated according to Tukey Test $(p<0.001))$. 
Table 2. Occurrence and concentrations of the positive identified analytes in natural grass samples during 2011 and 2014.

\begin{tabular}{|c|c|c|c|c|c|c|c|c|c|c|}
\hline \multirow{2}{*}{ Analyte } & \multirow{2}{*}{$\begin{array}{c}\mathrm{N}^{\circ} \text { of } \\
\text { Positives }\end{array}$} & \multicolumn{4}{|c|}{$\begin{array}{c}\text { Concentration of Positive Samples from } 2011 \\
(\mu \mathrm{g} / \mathrm{kg} \mathrm{d.m.})\end{array}$} & \multirow{2}{*}{$\begin{array}{c}\mathrm{N}^{\circ} \text { of } \\
\text { Positives }\end{array}$} & \multicolumn{4}{|c|}{$\begin{array}{c}\text { Concentration in Positive Samples from } 2014 \\
(\mu \mathrm{g} / \mathrm{kg} \mathrm{d.m.)}\end{array}$} \\
\hline & & Median & $\begin{array}{c}75 \\
\text { Percentile }\end{array}$ & $\begin{array}{c}90 \\
\text { Percentile }\end{array}$ & Max & & Median & $\begin{array}{c}75 \\
\text { Percentile }\end{array}$ & $\begin{array}{c}90 \\
\text { Percentile }\end{array}$ & $\operatorname{Max}$ \\
\hline T-2 toxin & $67 / 106$ & 37.8 & 218 & 1375 & 5438 & $39 / 69$ & 47.2 & 243 & 559 & 1095 \\
\hline HT-2 toxin & $52 / 106$ & 110 & 474 & 1149 & 5651 & $29 / 60$ & 66.5 & 117 & 205 & 783 \\
\hline Diacetoxyscirpenol & $2 / 106$ & 13.6 & 21.5 & 21.5 & 21.5 & $2 / 69$ & 6.49 & 10.5 & 10.5 & 10.5 \\
\hline Neosolaniol & $36 / 106$ & 10.4 & 39.0 & 94.5 & 187 & $11 / 69$ & 19.4 & 38.1 & 39.6 & 39.9 \\
\hline Nivalenol & $15 / 106$ & 21.0 & 44.3 & 63.6 & 66.9 & $2 / 69$ & 422 & 832 & 832 & 831 \\
\hline Zearalenone & $95 / 106$ & 7.20 & 50.3 & 203 & 2120 & $56 / 69$ & 2.50 & 10.0 & 80.2 & 712 \\
\hline Zearalenone-4-sulfate & $67 / 106$ & 3.10 & 13.0 & 99.4 & 303 & $17 / 69$ & 6.81 & 35.7 & 87.4 & 111 \\
\hline$\alpha$-zearalenol & $53 / 106$ & 10.7 & 39.4 & 181 & 464 & $12 / 69$ & 9.37 & 45.1 & 154 & 360 \\
\hline$\beta$-zearalenol & $28 / 106$ & 10.9 & 34.9 & 53.9 & 245 & $7 / 69$ & 8.35 & 24.2 & 47.5 & 52.8 \\
\hline Fumonisin $\mathrm{B}_{1}$ & $11 / 106$ & 57.2 & 97.0 & 442 & 566 & $2 / 69$ & 64.0 & 98.7 & 98.7 & 98.7 \\
\hline Moniliformin & $12 / 106$ & 13.5 & 56.2 & 152 & 313 & $3 / 69$ & 4.38 & 5.3 & 5.64 & 5.64 \\
\hline Beauvericin & $106 / 106$ & 13.5 & 33.2 & 95.1 & 624 & $43 / 69$ & 2.23 & 9.1 & 18.5 & 63.4 \\
\hline Enniatin B & $74 / 106$ & 0.09 & 0.17 & 0.47 & 43.2 & $4 / 69$ & 0.05 & 0.10 & 0.14 & 0.14 \\
\hline Aurofusarin & $96 / 106$ & 71.4 & 231 & 508 & 13238 & $25 / 69$ & 80.7 & 195 & 365 & 409 \\
\hline Equisetin & $106 / 106$ & 118 & 624 & 2841 & 17264 & $63 / 69$ & 2.21 & 12.8 & 54.8 & 297 \\
\hline Sterigmatocystin & $96 / 106$ & 4.15 & 16.5 & 42.6 & 733 & $41 / 69$ & 6.78 & 15.1 & 53.8 & 147 \\
\hline Averantin & $85 / 106$ & 1.60 & 5.07 & 19.4 & 499 & $65 / 69$ & 1.16 & 2.60 & 25.3 & 319 \\
\hline Averufanin & $51 / 106$ & 0.70 & 1.55 & 4.44 & 17.5 & $21 / 69$ & 0.20 & 0.54 & 3.73 & 4.65 \\
\hline Averufin & $67 / 106$ & 3.80 & 8.57 & 20.4 & 173 & $67 / 69$ & 2.78 & 8.00 & 49.3 & 401 \\
\hline Versicolorin A & $20 / 106$ & 0.65 & 1.35 & 27.4 & 46.5 & $38 / 69$ & 3.08 & 11.9 & 103 & 719 \\
\hline Versicolorin $\mathrm{C}$ & $33 / 106$ & 1.50 & 2.42 & 4.22 & 25.3 & $47 / 69$ & 3.36 & 10.1 & 43.9 & 209 \\
\hline
\end{tabular}


Table 2. Cont.

\begin{tabular}{|c|c|c|c|c|c|c|c|c|c|c|}
\hline \multirow{2}{*}{ Analyte } & \multirow{2}{*}{$\begin{array}{c}\mathrm{N}^{\circ} \text { of } \\
\text { Positives }\end{array}$} & \multicolumn{4}{|c|}{$\begin{array}{c}\text { Concentration of Positive Samples from } 2011 \\
(\mu \mathrm{g} / \mathrm{kg} \text { d.m. })\end{array}$} & \multirow{2}{*}{$\begin{array}{c}\mathbf{N}^{\circ} \text { of } \\
\text { Positives }\end{array}$} & \multicolumn{4}{|c|}{$\begin{array}{c}\text { Concentration in Positive Samples from } 2014 \\
(\mu \mathrm{g} / \mathrm{kg} \mathrm{d} \text { d.m. })\end{array}$} \\
\hline & & Median & $\begin{array}{c}75 \\
\text { Percentile } \\
\end{array}$ & $\begin{array}{c}90 \\
\text { Percentile } \\
\end{array}$ & $\operatorname{Max}$ & & Median & $\begin{array}{c}75 \\
\text { Percentile } \\
\end{array}$ & $\begin{array}{c}90 \\
\text { Percentile } \\
\end{array}$ & $\operatorname{Max}$ \\
\hline Nidurufin & $41 / 106$ & 0.60 & 41.2 & 91.1 & 228 & $30 / 69$ & 0.87 & 3.58 & 10.1 & 28.3 \\
\hline Norsolorinic acid & $59 / 106$ & 3.60 & 23.4 & 93.6 & 257 & $44 / 69$ & 3.55 & 6.76 & 23.7 & 63.1 \\
\hline Kojic acid & $39 / 106$ & 206 & 329 & 404 & 522 & $66 / 69$ & 103 & 127 & 139 & 187 \\
\hline 3-nitropropionic acid & $32 / 106$ & 2.70 & 5.70 & 9.94 & 28.8 & $37 / 69$ & 3.77 & 1.91 & 28.0 & 102 \\
\hline Aspinolid B & $40 / 106$ & 39.2 & 82.6 & 186 & 602 & $27 / 69$ & 10.0 & 25.0 & 43.7 & 423 \\
\hline Asterric acid & $44 / 106$ & 33.6 & 58.8 & 141 & 346 & $26 / 69$ & 22.9 & 58.3 & 140.2 & 223 \\
\hline Sulochrin & $42 / 106$ & 23.7 & 62.6 & 90.1 & 198 & $30 / 69$ & 18.3 & 52.7 & 283 & 172 \\
\hline Pseurotin A & $31 / 106$ & 4.70 & 8.37 & 13.4 & 15.2 & $10 / 69$ & 7.88 & 23.4 & 148 & 29.5 \\
\hline Agroclavine & $2 / 106$ & 11.2 & 14.0 & 14.0 & 14.0 & $1 / 69$ & & & & \\
\hline Chanoclavin & $69 / 106$ & 2.60 & 49.1 & 180.6 & 2259 & $31 / 69$ & 2.44 & 45.1 & 439 & 815 \\
\hline Festuclavine & $5 / 106$ & 32.1 & 93.6 & 98.4 & 98.4 & $5 / 69$ & 7.63 & 75.6 & 215 & 215 \\
\hline Secalonic acid & $28 / 106$ & 72.9 & 116 & 229 & 1431 & $7 / 69$ & 36.5 & 202 & 230 & 236 \\
\hline Griseofulvin & $30 / 106$ & 18.9 & 150 & 594 & 5880 & $4 / 69$ & 23.4 & 75.0 & 123 & 123 \\
\hline Dechlorogriseofulvin & $18 / 106$ & 16.2 & 124 & 270 & 3904 & $2 / 69$ & 20.0 & 32.5 & 32.5 & 32.5 \\
\hline Dihydrogriseofulvin & $20 / 106$ & 17.4 & 119 & 333 & 5720 & $3 / 69$ & 14.2 & 55.6 & 69.4 & 69.4 \\
\hline Curvularin & $73 / 106$ & 9.30 & 39.7 & 358 & 5362 & $14 / 69$ & 5.10 & 8.62 & 121 & 934 \\
\hline Brefeldin A & $2 / 106$ & 1648 & 2988 & 2988 & 2988 & $2 / 69$ & 745 & 874 & 874 & 875 \\
\hline Penicillide & $7 / 106$ & 5.70 & 10.1 & 14.1 & 14.9 & $1 / 69$ & 15.4 & & & \\
\hline Tenuazonic acid & $28 / 106$ & 31.4 & 59.4 & 141 & 222 & $27 / 69$ & 2.43 & 4.67 & 11.3 & 178 \\
\hline Alternariol & $105 / 106$ & 65.3 & 160. & 349 & 1036 & $61 / 69$ & 17.4 & 58.0 & 136 & 1021 \\
\hline Alternariol methyl ether & $67 / 106$ & 12.6 & 33.3 & 69.2 & 377 & $67 / 69$ & 10.5 & 20.2 & 39.2 & 160 \\
\hline Tentoxin & $90 / 106$ & 1.60 & 4.30 & 12.8 & 324 & $21 / 69$ & 3.76 & 21.3 & 136 & 252 \\
\hline
\end{tabular}


Table 2. Cont.

\begin{tabular}{|c|c|c|c|c|c|c|c|c|c|c|}
\hline \multirow{2}{*}{ Analyte } & \multirow{2}{*}{$\begin{array}{c}\mathbf{N}^{\circ} \text { of } \\
\text { Positives }\end{array}$} & \multicolumn{4}{|c|}{$\begin{array}{c}\text { Concentration of Positive Samples from } 2011 \\
(\mu \mathrm{g} / \mathrm{kg} \text { d.m. })\end{array}$} & \multirow{2}{*}{$\begin{array}{c}\mathrm{N}^{\circ} \text { of } \\
\text { Positives }\end{array}$} & \multicolumn{4}{|c|}{$\begin{array}{c}\text { Concentration in Positive Samples from } 2014 \\
(\mu \mathrm{g} / \mathrm{kg} \text { d.m. })\end{array}$} \\
\hline & & Median & $\begin{array}{c}75 \\
\text { Percentile } \\
\end{array}$ & $\begin{array}{c}90 \\
\text { Percentile } \\
\end{array}$ & $\operatorname{Max}$ & & Median & $\begin{array}{c}75 \\
\text { Percentile } \\
\end{array}$ & $\begin{array}{c}90 \\
\text { Percentile } \\
\end{array}$ & Max \\
\hline Altenuene & $23 / 106$ & 10.3 & 15.5 & 19.8 & 28.4 & $2 / 69$ & 14.3 & 18.7 & 18.7 & 18.7 \\
\hline Altertoxin-I & $75 / 106$ & 5.00 & 9.40 & 15.6 & 383 & $5 / 69$ & 1.43 & 1.86 & 2.72 & 2.72 \\
\hline Macrosporin & $60 / 106$ & 2.85 & 8.90 & 21.8 & 50.4 & $17 / 69$ & 1.95 & 4.53 & 19.2 & 76.2 \\
\hline Clonostachydiol & $13 / 106$ & 11.5 & 21.4 & 53.0 & 121 & $3 / 69$ & 9.97 & 71.9 & 92.6 & 92.6 \\
\hline Cytochalasin B & $10 / 106$ & 90.0 & 136 & 925 & 1616 & $6 / 69$ & 32.6 & 42.6 & 91.6 & 97.0 \\
\hline Cytochalasin $\mathrm{C}$ & $14 / 106$ & 27.9 & 64.6 & 264 & 412 & $3 / 69$ & 33.6 & 38.1 & 39.5 & 39.5 \\
\hline Cytochalasin D & $10 / 106$ & 24.6 & 67.2 & 87.6 & 106 & $6 / 69$ & 9.28 & 10.3 & 24.1 & 25.6 \\
\hline Cytochalasin $\mathrm{H}$ & $9 / 106$ & 368 & 1152 & 1802 & 2003 & $4 / 69$ & 163 & 638 & 1064 & 1064 \\
\hline Cytochalasin J & $20 / 106$ & 40.8 & 133 & 215 & 434 & $4 / 69$ & 122 & 436 & 677 & 677 \\
\hline Monocerin & $106 / 106$ & 66.7 & 215 & 1916 & 6745 & $65 / 69$ & 20.7 & 46.9 & 642 & 7289 \\
\hline Brevianamid F & $33 / 106$ & 8.00 & 11.2 & 17.1 & 34.3 & $18 / 69$ & 32.3 & 36.1 & 49.0 & 62.5 \\
\hline Tryptophol & $75 / 106$ & 73.1 & 113 & 217 & 466 & $67 / 69$ & 67.3 & 226.8 & 1070 & 2513 \\
\hline Emodin & $106 / 106$ & 177 & 471 & 1551 & 3725 & $67 / 69$ & 62.1 & 95.4 & 282 & 5401 \\
\hline Chrysophanol & $104 / 106$ & 41.1 & 77.8 & 142 & 15952 & $63 / 69$ & 15.5 & 24.8 & 47.6 & 120 \\
\hline Physcion & $74 / 106$ & 69.9 & 166 & 391 & 17752 & $7 / 69$ & 31.7 & 35.4 & 45.9 & 48.4 \\
\hline Skyrin & $105 / 106$ & 5.90 & 14.2 & 38.3 & 241 & $55 / 69$ & 1.93 & 2.67 & 5.42 & 13.7 \\
\hline Radicicol & $50 / 106$ & 33.2 & 95.0 & 182 & 380 & $20 / 69$ & 17.5 & 56.5 & 75.0 & 210 \\
\hline
\end{tabular}


During 2014, monocerin and equisetin were also present in $\geq 90 \%$ whereas zearalenone was present in $81 \%$ of the samples analyzed. Other Fusarium mycotoxins detected at a prevalence of $40 \%-70 \%$ were T-2 toxin, HT-2 toxin and beauvericin. Aurofusarin, zearalenone- 4 sulfate, $\alpha$-zearalenol and neosolaniol were detected at frequencies of $36 \%, 25 \%, 17 \%$ and $16 \%$, respectively. $\beta$-zearalenol, enniantin B, moniliformin, diacetoxyscirpenol, nivalenol and fumonisin $\mathrm{B}_{1}$ were found in low abundance $\leq 10 \%$.

In particular, out of 106 natural grass samples collected during 2011, 95 were contaminated with zearalenone in concentrations ranging from $0.7-2120 \mu \mathrm{g} / \mathrm{kg} \mathrm{d} . \mathrm{m}$. (mean $=84.5 \mu \mathrm{g} / \mathrm{kg}$ ). Also, 52 grass samples were co-contaminated with zearalenone and $\alpha$-zearalenol, both precursors of zeranol, while 22 samples showed co-occurrence of zearalenone, $\alpha$-zearalenol and $\beta$-zearalenol. In the 2014 grass samples, 56 out of 69 samples contaminated with zearalenone in concentrations ranging from $0.3-711.80 \mu \mathrm{g} / \mathrm{kg} \mathrm{d.m}$. (mean $=41.40 \mu \mathrm{g} / \mathrm{kg} \mathrm{d.m}$.) were found. Also, seven grass samples were co-contaminated with zearalenone and $\alpha$-zearalenol, both precursors of zeranol, and seven samples showed co-occurrence of zearalenone, $\alpha$-zearalenol and $\beta$-zearalenol.

Alternariol was the most frequent (99\%) Alternaria mycotoxin found on natural grasses during 2011. Tentoxin, altertoxin-1, alternariol monomethyl ether and macrosporin were detected in frequencies ranging from $85 \%$ to $57 \%$. Tenuazonic acid was detected in $26 \%$ of the samples analysed.

Alternariol monomethyl ether was the most frequent (97\%) Alternaria mycotoxin found on natural grasses during 2014. Alternariol, tenuazonic acid, tentoxin and macrosporin were detected in frequencies ranging from $88 \%$ to $25 \%$. Altertoxin-I was detected at very low frequency $(7 \%)$ in the samples analysed.

Aflatoxin was not detected in any grass sample analysed during both years evaluated, but sterigmatocystin and some of its precursors exhibited a very high prevalence (sterigmatocystin: 90\% in 2011 and 60\% in 2014; averantin; 80\% in 2011 and 99\% in 2014). Averufin, norsolorinic acid, averufanin, versicolorin $\mathrm{C}$, nidurufin and versicolorin A were detected in frequencies $>20 \%$ during both years.

Chanoclavin and curvularin were the most frequent Penicillium mycotoxin found on natural grass during both those years analyzed. Another eight metabolites (agroclavine, festuclavine, secalonic acid, dihydrogriseofulvin, dechlorogriseofulvin, brefeldin A and penicillide) produced by Penicillium species were also detected, but in low abundance $\leq 27 \%$ (see Table 1). Although some metabolites such as griseofulvin, dihydrogriseofulvin, dechlorogriseofulvin among others were found in low frequency, the maximum concentrations detected were very high in some samples.

Anthraquinones such as chrysophanol, emodin and skyrin that may be produced both by fungi and plants, were detected in high frequency $(>80 \%)$ during both years and also at very high levels in some samples. However, physcion was detected in high frequency just in 2011 samples.

Cytochalasin B, C, D, H and J were detected in low frequency $(\leq 20 \%)$, but some of them such as cytochalasin B was found in high concentration in some samples $(1616 \mu \mathrm{g} / \mathrm{kg})$.

The bacterial metabolite monactin was found at low prevalence $(\leq 10 \%)$ and also at low levels only in grass samples collected during 2011 (data not shown). 


\section{Discussion}

To our knowledge, the present study represents the first survey on multi-mycotoxin contamination occurrence in natural grasses used for beef animal production. It was noticeable that the LC-MS/MS method applied possessed the performance characteristics required to obtain accurate results. Out of the 175 natural grass samples analysed, all showed contamination, being co-occurrence the rule. The use of the multi-metabolites LC-MS/MS method allowed us to ascertain the extent of the natural grasses' contamination. It is important to remark that the beef cattle grazing on both farms evaluated during 2011 and 2014 did not show any symptoms of mycotoxicosis. Since our main goal was to demonstrate that the farmers did not abuse the use of zeranol, we obtained samples in 2011, a year after the finding of zeranol in urine among cattle from both farms, in the paddocks where the cattle were grazing the year before. As we used a multi-toxin analytical method, we were able to detect co-occurrence of zearalenone and several metabolites for the first time in natural grasses. We conducted other sampling during 2014 in order to probe that our first findings were not a sporadic event, and to probe that it is normal to find zearalenone and other mycotoxins on natural grasses (uncultivated).

Numerous mycotoxins can be produced by fungi invading plant material; however, only few mycotoxins have been recognized as toxic to ruminants. The toxins detected in the present survey included the major mycotoxins of concern for ruminant health such as zearalenone, and trichothecenes, and others still not evaluated [4].

Common knowledge on animal mycotoxicosis indicates that ruminant animals are among the least susceptible animal species, as the rumen microflora effectively degrade and inactivate mycotoxins, hence protecting the animal [5]. Some microbes from the rumen have been identified for their ability to degrade mycotoxins or plant toxins. Among the first mycotoxins shown to be detoxified by ruminants were ochratoxin $\mathrm{A}[14]$, and aflatoxin $\mathrm{B}_{1}[15,16]$. The metabolism of different mycotoxins potentially encountered by ruminants has also been investigated, and it has been found that the mycotoxins zearalenone, T-2 toxin, diacetoxyscirpenol and deoxynivalenol were well metabolized by whole rumen fluid, whereas aflatoxin $B_{1}$ and ochratoxin A were not [17]. Kennedy et al. [9] reported that 90\% of zearalenone was hydrolyzed to $\alpha$-zearalenol by rumen microbes. Although the $\alpha$ form of zearalenone is more estrogenic than its parent form, due to the low rate of absorption, ruminants are less susceptible to zearalenone toxicity [18].

Among the few mycotoxins considered toxic for ruminants, none of the natural grass samples collected in both years were contaminated with aflatoxins, ochratoxin A, ergot alkaloids, gliotoxin among others. However, we were able to detect important metabolites such as trichothecenes type A, and $\mathrm{B}$, sterigmatocistin and zearalenone.

Data on zearalenone and derivates detected during the present study are of concern if we consider, as an example, that beef cattle need to eat $10 \%$ of their weight body per day; an animal of $400 \mathrm{~kg}$ needs to eat $40 \mathrm{~kg}$ of natural grasses a day. Considering our results, $40 \mathrm{~kg}$ of natural grasses will result in an average daily intake of $3.38 \mathrm{mg}$ of zearalenone and $2.0 \mathrm{mg} \alpha$-zearalenol per animal. Kleinova et al. [19] when feeding heifers with similar amounts of zearalenone (oat contaminated with $2.74 \mathrm{mg}$ zearalenone per animal) and a control group with zeranol implant (25 $\mathrm{mg})$, found in urine samples of the treated and control animals similar concentrations of zeranol ( $\alpha$-zearalanol) and taleranol ( $\beta$-zearalanol). In addition, in the heifers that have consumed oat contaminated with 
zearalenone, zearalenone, $\alpha$-zearalenol and $\beta$-zearalenol in urine were also found. The present study showed that the presence of zeranol in urine of beef cattle could be not a consequence of illegal use of this banned substance, but the product of the natural occurrence of zearalenone and $\alpha$-zearalenol in natural grasses intended for cattle feeding. The high prevalence of these metabolites during both years is remarkable being that their presence is not a sporadic event.

It is important to highlight the presence of zearalenone-4-sulfate in natural grass samples during both years. Sulfo-conjugation is part of the phase II detoxification process that plants and animals use to inactivate mycotoxins and other xenobiotics. It has also been demonstrated by Berthiller et al. [20] that Arabidopsis thaliana seedlings treated with zearalenone produced also zearalenone-4-sulfate. Zearalenone-4-sulfate formation seems to be a mechanism of self-protection. Despite its chemical alteration, there is evidence that the above mentioned metabolite has a similar toxic potential to those of their precursors when ingested with food, as attached functional groups like sulfate residues are likely to be enzymatically cleaved during digestion [21].

Among the type A trichothecenes, T-2 toxin, HT-2 toxin, neosolaniol and diacetoxyscirpenol were found in 2011 and 2014 and we did not find any significant differences in this group of mycotoxins between both years analysed. Some grass samples from 2011 showed very high concentration of T-2 toxin and HT-2 toxin, up to $5000 \mu \mathrm{g} / \mathrm{kg} \mathrm{d.m}$. each during 2011. T-2 and HT-2 toxin, the most prominent type A trichothecenes, often found together in plants, are some of the most toxic trichothecene detected in feed for cattle. Ruminants can rapidly de-acetylate T-2 toxin to HT-2 [22]. It is often difficult to distinguish the effects of T-2 toxin from HT-2 toxin in vivo; therefore, it is reasonable to sum up the concentrations of these toxins to evaluate clinical effects. T-2 toxin ingestion results in a severe irritation of the upper digestive tract, including a hemorrhagic ruminitis, due to its cytotoxic effects. The T-2 toxin is also believed to induce immune-suppression in cattle by decreasing serum concentrations of IgM, IgG and IgA, neutrophil functions and lymphocyte blastogenesis. Bovine infertility and abortion in the final trimester of gestation have also resulted from the consumption of feed contaminated with T-2 [6]. With the exception of T-2 toxin, cattle have not been adversely affected by others trichothecenes. The high levels of type A trichothecenes (especially T-2 and HT-2 toxins) can be explained due to the Fusarium species contamination. This assertion is supported by the mycological analysis of 2011 grass samples, which revealed that $100 \%$ of the samples were contaminated with Fusarium, being $F$. armeniacum the most common species found. Also, we have demonstrated that 50 selected $F$. armeniacum isolates were able to produce a broad range of type A trichothecenes (including T-2, HT-2, neosolaniol among others) [23]. Consequently, F. armeniacum could be responsible for the high prevalence of type A trichotheces on natural grasses analysed during the present study.

Deoxynivalenol and nivalenol were the only trichothecene type B found in natural grasses, at very low frequencies and levels during 2011. Deoxynivalenol was not present in 2014, while nivalenol was found at very low frequency but at higher concentrations than in 2011. Deoxynivalenol, the most prominent type B trichothecene present in cattle feed worldwide, is not considered to be acutely toxic; it is considered to be a major cause of economic loss due to reduced performance. Clinical signs include gastrointestinal problems, soft stools, diarrhea, increased susceptibility to other diseases and decreased performance. Cattle are resistant to the emetic effects of deoxynivalenol, but reduced food intake was observed at $10-20 \mathrm{mg} / \mathrm{kg}$ in ruminants [24]. During the present work, deoxynivalenol was 
detected in few samples $(n=9)$ and at concentrations lower than the guidance value provided by the European Commission for bovine feed. Nivalenol was found in low prevalence $(22 \%$ and $3 \%)$ with all sample values below $831.80 \mu \mathrm{g} / \mathrm{kg}$ d.m., thereby presenting contamination levels within the range of surveys conducted elsewhere [25-29]. The risk associated with chronic exposure to low levels of nivalenol in animal feed is difficult to evaluate due to the limited data available in farm animals.

It is generally assumed that within the rumen the protozoal population has the highest capacity to detoxify ingested myctoxins, but this may vary between different classes of mycotoxins. The contribution of bacteria and other rumen organisms might have been underestimated, as generally only the overall capacity to degrade a given mycotoxin has been tested [27]. Several mycotoxins are, however, able to modify the rumen microbiota as they exert antimicrobial, anti-protozoal and antifungal activity; typical examples are patulin, fusaric acid, beauvericin and enniantins. The findings that mycotoxins impair the rumen microbiota correspond to the observation in clinical practice where, following a period of feeding mould contaminated silage to dairy cows, a reduced filling of the rumen, poor feed conversion, and mild diarrhea are observed [30,31]. The co-occurrence of mycotoxins observed in the present study is relevant considering their potential effects on the rumen microbiota.

Enniatins and beauvericin are cytotoxic cyclic hexadepsipeptides produced by several Fusarium species and are known to be toxic to insects, bacteria and fungi [32]. Enniatin B was the most prevalent enniatin mycotoxin, present in $70 \%$ of the samples during 2011 , but all the enniatins were found in very low concentrations. In 2014 samples, enniantin B was the only one enniantin detected at very low frequency and levels. Beauvericin was present in all analysed grass samples in 2011 and in 43 during 2014, at levels within the concentration range reported by other studies [33,34]. There are no data that indicate that beauvericin has potential toxicity to cattle.

The occurrence of alternariol, alternariol methyl ether, tentoxin and altertoxin I was high in the analysed samples (99\%-70\%) during 2011. Although, in samples from 2014, alternariol and alternariol methyl ether were present at very high frequencies $(88 \%$ and $97 \%)$, tentoxin and altertoxin I were found at lower frequencies than in 2011. Overall, maximum levels of alternariol were higher than those reported in the literature with the exception of sunflower. Alternaria species produce more than 70 phytotoxins, but a small proportion of them has been chemically characterized and reported to act as mycotoxins to humans and animals. Some toxins such as alternariol, alternariol methyl ether, tenuazonic acid and altertoxins are described to induce harmful effects in animals, including fetotoxic and teratogenic effects. At present, knowledge of the possible effects of Alternaria toxins on farm and companion animals as well as the database describing the occurrence of these mycotoxins in feedstuffs are scarce and insufficient to assess the risk regarding Alternaria toxins for animal health [35].

Occurrence data on equisetin and monocerin on animal feed are very limited [36]. Both mentioned metabolites were found at very high frequencies in both years $(>90 \%)$ and at very high concentration in some samples analysed in the present study. Equisetin was reported as a metabolite of $F$. equiseti and F. semitectum with weak activity against gram-positive bacteria and other cytotoxic activities [37]. Equisetin has been found as a natural contaminant in corn, wheat silage and corn silage but at concentrations lower than those obtained during the present study [36,38]. Monocerin is a polyketide fungal metabolite that exhibits antifungal, insecticidal, and plant pathogenic properties. It has been isolated from several fungal species [39]. Monocerin was present in all grass samples under study, 
at relatively high concentrations comparable with those found by Shimshoni et al. [36] on corn silage. The toxic effect of this metabolite on ruminants is still unknown.

Aflatoxins were not detected during the present study, although we were able to detect several precursors (some at very high frequencies) in the biosynthetic aflatoxin (AF) pathway. This suggests Aspergillus versicolor as the fungal producer The general accepted AF biosynthetic pathway scheme is: A hexanol CoA precursor $\rightarrow$ norsolorinic acid, NOR $\rightarrow$ averantin, AVN $\rightarrow$ hydroxyaverantin, HAVN $\rightarrow$ Oxoaverantin, OAVN $\rightarrow$ averufin, AVF $\rightarrow$ Hydroxyversicolorone, HVN $\rightarrow$ versiconal hemicetal acetate, VHA $\rightarrow$ versiconal, VAL $\rightarrow$ versicolorin $\mathrm{B}$, VERB $\rightarrow$ versicolorin A, VERA $\rightarrow$ demethyl-sterigmatocystin, DMST $\rightarrow$ sterigmatocystin , ST O-methylsterigmatocystin, OMST $\rightarrow$ aflatoxin $\mathrm{B}_{1}, \mathrm{AFB}_{1}$ and aflatoxin $\mathrm{G}_{1}, \mathrm{AFG}_{1}$. After the VHA step, there is a branch point in the pathway that leads to $\mathrm{AFB}_{1}$ and $\mathrm{AFG}_{1}$ formation as well as $\mathrm{AFB}_{2}$ and $\mathrm{AFG}_{2}$ [40]. In particular $\mathrm{ST}$, the penultimate precursor of AF, is produced by more than 50 fungal species, including Aspergillus flavus, $A$. parasiticus, $A$. versicolor and $A$. nidulans, of which $A$. versicolor is the most common source. ST shares its biosynthetic pathway with aflatoxins. A. nidulans and A. versicolor are apparently unable to biotransform ST into OMST, the direct precursor of $\mathrm{AFB}_{1}$ and $\mathrm{AFG}_{1}$. Consequently, substrates colonized by these fungi can contain high amounts of ST, while substrates invaded by A. flavus and A. parasiticus contain only low amounts of ST as most of it is converted into AFs. ST was detected in $90 \%$ and $60 \%$ of the grass samples analysed during 2011 and 2014 , respectively. Owing to the structural similarities, AFs and ST share prominent toxic effects, including genotoxicity and carcinogenicity, being the AFs considered 150-200 times more potent than ST [41]. However, in contrast to AFs, only limited information on occurrence and toxicity of ST is available. Only limited data are available for other ruminants, but a case report describes haemorrhages and bloody diarrhea in cattle following exposure to ST [42]. Some grass samples showed very high levels of contamination with ST (up to $730 \mu \mathrm{g} / \mathrm{kg} \mathrm{d.m}$.) if we consider the guidance of the European Parliament [43] for feed, the concentration of ST must be regarded as significant.

Among the Penicillium metabolites, we were unable to detect in any samples patulin, mycophenolic acid, roquefortine $\mathrm{C}$ and $\mathrm{PR}$ toxin that are common mycotoxins found in grass silage around the world [44].

Several infrequently reported anthraquinone derivates produced by fungi and plants were found during the present research, such as emodin, its methy-derivate physcion and chrysophanol and its respective dimer skyrin. The high maximum concentration detected of the above mentioned metabolites is also remarkable, mainly in samples from 2011. All these anthraquinones are commonly found on plants belonging to the Poligonaceae family, and have been reported as antibacterial, anti-inflammatory, antiviral anti-ulcerogenic and anticancer agents. Also, all these compounds play well-documented roles as chemopreventive effects [45].

During this study we have detected one bacterial metabolite with antibiotic activity: monactin at very low frequency $(<10 \%)$ and concentrations in 2011 grass samples. This metabolite is a member of the macrotetrolide complex produced by a range of Streptomyces species [46]. At present, no data are available regarding the effect of this antibiotic present in grasses on ruminants.

We did not detect any of the indole-diterpenoid alkaloids in the natural grasses under study. These compounds are produced by species of the Claviceps genus within the Hypocreales that can infest plant species belonging to Poaceae (family of the true grasses). In Argentina, mycotoxicosis 
among cattle has been reported due to the presence of indol-diterpenoid tremorgens, produced by Claviceps paspali present in grasses such as Paspalum dilatatum and P. notatum and by Claviceps cynodontis present on Cynodon dactylon. Also, ryegrass staggers caused by the endophytic fungi Neotyphodium lolii (that produce indol-diterpenoid alkaloids) in Lolium perenne occurs frequently in cattle in Argentina. Gangrenous ergotism caused by C. purpurea and Festuca elation has also been observed [47].

This study showed new and original data on the presence of multi-fungal and bacterial metabolites on natural grasses (non-cultivated) used for grazing cattle. Only few studies have investigated the presence of mycotoxins but just on cultivated grasses used as forage (mainly silage) for cattle feeding, most of them focus on few mycotoxins such as deoxynivalenol, zearalenone, fumonisins and aflatoxins [48-50].

\section{Experimental Section}

\subsection{Sampling}

Natural grass samples were obtained from two beef cattle farms located in the Chaco province of Argentina, included in the Ramsar site. One hundred and six grass samples (53 from each farm) were collected during July 2011, and 69 during July 2014. On each farm, a paddock of around 1000 ha was chosen for sampling. Each sample, corresponding to one plant, was cut at ground level and transported to the laboratory in a paper bag. The aerial harvested portions of plants, including leaf and stems, were immediately oven dried at $60{ }^{\circ} \mathrm{C}$ for $48 \mathrm{~h}$ or until constant weight, indicating that the entire aqueous portion was extracted from plant tissues. Since the sampling was done during winter, it was not possible to identify the grasses up to species level due to the absence of inflorescence but we can confirm that all belong to the Poaceae family.

The two cattle farms were located in the wetland of Chaco region in Argentina. This region covers part of the Parana and Paraguay rivers floodplain complex in the eastern border of Chaco Province and it is limited to the north by the Bermejo River which surrounds the city of Resistencia. The hydrological regimes of each river give rise to different pulses of flood and drought in these wetlands, regulating flood downstream and retaining waters in times of drought. The landscape is complex open water, aquatic vegetation, grasslands and gallery forests. The annual temperature ranges between 20 and $24{ }^{\circ} \mathrm{C}$. Maximum absolute temperatures can peak at $46.5{ }^{\circ} \mathrm{C}$. Mean annual rainfall is $1300 \mathrm{~mm}$, concentrated in spring and summer. The most common species of grasses in the area under study are Leersia hexandra, Luziola peruviana, Sorghastrum setosum, Spartina argentinensis, Cynodon dactylon between others [51].

\subsection{Mycotoxin Analysis}

\subsubsection{Chemicals and Reagents}

Methanol (LC gradient grade) and glacial acetic acid (p.a.) were purchased from Merck (Darmstadt, Germany), acetonitrile (LC gradient grade) from VWR (Leuven, Belgium), and ammonium acetate 
(MS grade) from Sigma-Aldrich (Vienna, Austria). Water was purified successively by reverse osmosis and an Elga Purelab ultra analytic system from Veolia Water (Bucks, UK) to 18.2 M 2 .

Standards of fungal and bacterial metabolites were obtained either as gifts from various research groups or from the following commercial sources: Romer Labs ${ }^{\circledR}$ Inc. (Tulln, Austria), Sigma-Aldrich (Vienna, Austria), Iris Biotech GmbH (Marktredwitz, Germany), Axxora Europe (Lausanne, Switzerland) and LGC Promochem GmbH (Wesel, Germany). Stock solutions of each analyte were prepared by dissolving the solid substance in acetonitrile (preferably), acetonitrile/water 1:1 ( $v / v)$, methanol, methanol/water 1:1 $(v / v)$ or water. Thirty-four combined working solutions were prepared by mixing the stock solutions of the corresponding analytes for easier handling, and were stored at $-20{ }^{\circ} \mathrm{C}$. The final working solution was freshly prepared prior to spiking experiments by mixing the combined working solutions.

\subsubsection{Extraction and Estimation of Apparent Recoveries}

Three grams of each grass sample, previously pulverized in a mill with a $1 \mathrm{~mm}^{2}$ mesh (Cyclotech, Foss Tecator, Höganäs, Sweden), were weighed into a $50 \mathrm{~mL}$ polypropylene tube (Sarstedt, Nümbrecht, Germany) and $20 \mathrm{~mL}$ of the extraction solvent (acetonitrile/water/acetic acid 79:20:1, v/v/v) were added. For spiking experiments, $0.25 \mathrm{~g}$ sample was used for extraction. Samples were extracted for 90 min on a GFL 3017 rotary shaker (GFL, Burgwedel, Germany) and diluted $1+1$ with dilution solvent (acetonitrile/water/acetic acid 20:79:1, v/v/v). Five microliters of the diluted extracts were subsequently injected [13].

\subsubsection{LC-MS/MS Parameters}

The LC-MS/MS has been previously described by Vishwanath et al. [52], but has been transformed to a more sensitive mass spectrometer and has been further extended [12]. Analysis was performed with a QTrap 5500 LC-MS/MS System (Applied Biosystems, Foster City, CA, USA) equipped with TurboIonSpray electrospray ionization (ESI) source and a 1290 Series HPLC System (Agilent, Waldbronn, Germany). Chromatographic separation was performed at $25{ }^{\circ} \mathrm{C}$ on a Gemini C18-column, $150 \times 4.6 \mathrm{~mm}$ i.d., $5 \mu \mathrm{m}$ particle size, equipped with a $\mathrm{C} 184 \times 3 \mathrm{~mm}$ i.d. security guard cartridge (Phenomenex, Torrance, CA, USA).

ESI-MS/MS was performed in the time-scheduled multiple reaction monitoring (MRM) mode both in positive and negative polarities in two separate chromatographic runs per sample by scanning two fragmentation reactions per analyte. The MRM detection window of each analyte was set to its expected retention time $\pm 27 \mathrm{~s}$ and $\pm 48 \mathrm{~s}$ in the positive and the negative modes, respectively. Confirmation of positive analyte identification was obtained by the acquisition of two MRMs per analyte (with the exception of moniliformin and 3-nitropropionic acid, that exhibited only one fragment ion). This yielded 4.0 identification points according to the European Union Commission decision 2002/657 [53]. In addition, the LC retention time and the intensity ratio of the two MRM transitions agreed with the related values of an authentic standard within 0.1 min and $30 \%$, respectively.

Quantification was performed using external calibration based on serial dilution of a multi-analyte stock solution. Results were corrected by apparent recoveries that had been determined by spiking five different blank samples at two concentration levels. 


\subsection{Statistical Analysis}

Each particular metabolite concentration was evaluated by analysis of variance (ANOVA) to determine any differences between the years of sampling. The data were $\log 10$ transformed to create a normal distribution. When the analysis was statistically significant, the post hoc Tukey's multiple comparison procedure was used for separation of the means. Statistical significance was judged at the level $p \leq 0.01$. All the analyses were done using SigmaStat for Windows Version 2.03 (SPSS Inc., Chicago, IL, USA).

\section{Conclusions}

A broad range (up to 77) of fungal metabolites was present in natural grasses (Poaceae) during two different years, and co-occurrence was the rule. It is important to point out that the profile of common metabolites was shared during both years of sampling, and also that the occurrence of important metabolites is not an exceptional phenomenon but seems to be very common. Some metabolites present such as type A trichothecenes (T-2 and HT-2), zearalenone and derivates are of concern for ruminants. Partial degradation in the rumen does mean that they are less toxic to cattle than to other animals, but some of these degradation products can be more toxic than the original mycotoxin. There are some studies on synergistic effects and only a few of them include those metabolites that were the most prevalent in our study. So, it cannot be ruled out that low levels of several mycotoxins might be more problematic than high levels of an individual mycotoxin, due to their synergistic relationship.

\section{Acknowledgments}

This work was supported by grants from SECyT-UNRC and CONICET grant $\mathrm{N}^{\circ} 112201201$ 005525 CO (Consejo Nacional de Investigaciones Científicas y Técnicas). Nichea M.J. and Palacios S.A. are CONICET fellows and Ramirez M.L., Torres A.M., Chulze S.N. and Chiacchiera S.M. are members of the Research Career of CONICET. The LC-MS/MS system was funded by the Federal Country Lower Austria and co-financed by the European regional development fund of the European Union.

\section{Author Contributions}

M.J.N. and S.A.P. performed the samples collection and preparation, S.M.C., M.S. and R.K. performed the metabolites analysis. M.L.R., A.M.T. and S.N.C. conceived and designed the experiments. M.L.R. and M.J.N. analysed the data and wrote the paper. M.S., S.N.C. and A.M.T. revised the manuscript.

\section{Conflicts of Interest}

The authors declare no conflict of interest.

\section{References}

1. Arelovich, H.M.; Bravo, R.D.; Martinez, M.F. Development, characteristic, and trends for beef cattle production in Argentina. Anim. Front. 2011, 1, 37-45. 
2. Garcia, P.T.; Pensela, N.A.; Sancho, A.M.; Latimori, N.J.; Kloster, A.M.; Amigone, M.A.; Casal, J.J. Beef lipids in relation to animal breed and nutrition in Argentina. Meat Sci. 2008, 79, 500-508.

3. Rotolo, G.C.; Rydberg, T.; Lieblein, G.; Francis, C. Emergy evaluation of grazing cattle in Argentina's Pampas. Agric. Ecosyst. Environ. 2007, 119, 383-395.

4. Mostrom, M.; Jacobsen, B. Ruminant mycotoxicosis. Vet. Clin. N. Am. Food Anim. Pract. 2011, 27, 315-344.

5. Fink-Gremmels, J. Mycotoxins in cattle feeds and carry-over to dairy milk: A review. Food Addit. Contam. Part A. 2008, 25, 172-180.

6. Zain, M. Impact of mycotoxins on humans and animals. J. Saudi Chem. Soc. 2011, 15, 129-144.

7. Mathews, K.H.; Vanderveer, M. Beef Production, Markets, and Trade in Argentina and Uruguay: An Overview. Report Economic Research Service, USDA. Available online: http://www.ers.usda.gov/ publications/ldpm-livestock,-dairy,-and-poultry-outlook/ldpm-15901.aspx (accessed on 20 February 2015).

8. Alonso, V.A.; Pereyra, C.M.; Keller, L.A.M.; Dalcero, A.M.; Rosa, C.A.R.; Chiacchiera, S.M.; Cavaglieri, L.R. Fungi and mycotoxins in silage: An overview (Review). J. Appl. Microbiol. 2013, 115, 637-643.

9. Kennedy, D.G.; Hewitt, S.A.; McEvoy, J.D.; Currie, J.W.; Cannavan, A.; Blanchflower, W.J.; Elliot, C.T. Zeranol is formed from Fusarium sp. toxins in cattle in vivo. Food Adit. Contam. 1998, 15, 393-400.

10. Smith, J.F.; Morris, C.A. Review of zearalenone studies with sheep in New Zealand. Proc. N. Z. Soc. Anim. Prod. 2006, 66, 306-310.

11. Ramsar Convention Secretariat. The Ramsar Convention Manual: A Guide to the Convention on Wetlands (Ramsar, Iran, 1971), 6th ed.; Ramsar Convention Secretariat: Gland, Switzerland, 2013.

12. Malachova, A.; Sulyok, M.; Beltrán, E.; Berthiller, F.; Krska, R. Optimization and validation of a quantitative liquid chromatography - Tandem mass spectrometric method covering 295 bacterial and fungal metabolites including all relevant mycotoxins in four model food matrices. J. Chromatogr. A 2014, 1362, 145-156.

13. Sulyok, M.; Berthiller, F.; Kraska, R.; Shhuhmacher, R. Development and validation of a liquid chromatography/tandem mass spectrometric method for the determination of 39 mycotoxins in wheat and maize. Rapid Commun. Mass Spectrom. 2006, 20, 2649-2659.

14. Hult, K.; Telling, A.; Gatenbeck, S. Degradation of ochratoxin A in ruminants. Appl. Environ. Microbiol. 1976, 32, 443-444.

15. Allcroft, R.; Robert, B.A.; Lloyd, M.K. Excretion of aflatoxin in a lactating cow. Food Cosmet. Toxicol. 1968, 6, 619-625.

16. Engel, V.G.; Hagemeister, H. Untersuchungenueber den verblieb von aflatoxin $B_{1}$ im Verdaaundtarkt von Kuehen. Milchwissenschaft 1978, 33, 21-23.

17. Kiessling, K.H.; Pettersson, H.; Sandholm, K. Metabolism of aflatoxin, ochratoxin, zearalenone, and three trichothecenes by intact rumen fluid, rumen protozoa, and rumen bacteria. Appl. Environ. Microbiol. 1984, 47, 1070-1073.

18. Seeling, K.; Lebzien, P.; Danicke, S.; Spilke, J.; Sudekum, K.H.; Flachowsky, G. Effects of level of feed intake and Fusarium toxin contaminated wheat on rumen fermentation as well as on blood and milk parameters in cows. J. Anim. Physiol. Anim. Nutr. 2006, 90, 103-110. 
19. Kleinova, M.; Zöllner, P.; Kahlbacher, H.; Hochsteiner, W.; Lindner, W. Metabolic profiles of the mycotoxin zearalenone and of the growth promoter zeranol in urine, liver, and muscle of heifers. J. Agric. Food Chem. 2002, 50, 4769-4776.

20. Berthiller, F.; Werner, U.; Sulyok, M.; Krska, R.; Hauser, M.T.; Schuhmacher, R. Liquid chromatography coupled to tandem mass spectrometry (LC-MS/MS) determination of phase II metabolites of the mycotoxin zearalenone in the model plant Arabidopsis thaliana. Food Addit. Contam. 2006, 23, 1194-1200.

21. Plasencia, J.; Mirocha, C.J. Isolation and characterization of zearalenone sulfate produced by Fusarium spp. Appl. Environ. Microbiol. 1991, 57, 146-150.

22. Zhou, T.; He, J.; Gong, J. Microbial transformation of trichothecene mycotoxins. World Mycotoxin J. 2008, $1,23-30$.

23. Nichea, M.J.; Cendoya, E.; Zachetti, V.G.L.; Chiacchiera, S.M.; Sulyok, M.; Krska, R.; Torres, A.M.; Chulze, S.N.; Ramirez, M.L. Mycotoxin profile of Fusarium armeniacum isolated from natural grasses intended for cattle feed. World Mycotoxin J. 2015, 8, 451-457.

24. Osweiler, G.D. Mycotoxins-contemporary issues of food animal health and productivity. Vet. Clin. N. Am. Food Anim. Pract. 2000, 16, 511-530.

25. Eckard, S.; Wettstein, F.E.; Forrer, H.R.Y.; Vogelsang, S. Incidence of Fusarium species and mycotoxins in silage maize. Toxins 2011, 3, 949-967.

26. Schollenberger, M.; Müller, H.M.; Rüfle, M.; Suchy, S.; Plank, S.; Drochner, W. Natural occurrence of 16 Fusarium toxins in grains and feedstuffs of plant origin from Germany. Mycopathologia 2006, 161, 43-52.

27. Streit, E.; Schatzmayr, G.; Tassis, P.; Tzika, E.; Marin, D.; Taranu, I.; Tabuc, C.; Nicolau, A.; Aprodu, I.; Puel, O.; et al. Current situation of mycotoxin contamination and co-occurrence in animal feed-focus on Europe. Toxins 2012, 4, 788-809.

28. Sulyok, M.; Krska, R.; Schuhmacher, R. A liquid chromatography/tandem mass spectrometric multi-mycotoxin method for the quantification of 87 analytes and its application to semiquantitative screening of moldy food samples. Anal. Bioanal. Chem. 2007, 389, 1505-1523.

29. Van Asselt, E.D.; Azambuja, W.; Moretti, A.; Kastelein, P.; De Rijk, T.C.; Stratakou, I.; van der Fels-Klerx, H.J. A Dutch field study on fungal infection and mycotoxin concentrations in maize. Food Addit. Contam. 2012, 29, 1556-1565.

30. Hadley, G.; Wolf, C.; Harsh, S. Dairy cattle culling patterns, explanations, and implications. J. Dairy Sci. 2006, 89, 2286-2296.

31. Wenz, J.; Jensen, S.; Lombard, J.; Wagner, B.; Dinsmore, R. Herd management practices and their association with bulk tank somatic cell count on United States dairy operations. J. Dairy Sci. 2007, 90, 3652-3659.

32. Wang, Q.; Xu, L. Beauvericin, a bioactive compound produced by fungi: A short review. Molecules 2012, 17, 2367-2377.

33. Sulyok, M.; Krska, R.; Schuhmacher, R. Application of an LC-MS/MS based multi-mycotoxin method for the semi-quantitative determination of mycotoxins occurring in different types of food infected by moulds. Food Chem. 2010, 119, 408-416. 
34. Warth, B.; Parich, A.; Atehnkeng, J.; Bandyopadhyay, R.; Schuhmacher, R.; Sulyok, M.; Krska, R. Quantitation of mycotoxins in food and feed from Burkina Faso and Mozambique using a modern LC-MS/MS multitoxin method. J. Agric. Food Chem. 2012, 60, 9352-9363.

35. European Food Safety Authority. Scientific Opinion on the risks for animal and public health related to the presence of Alternaria toxins in feed and food. EFSA J. 2011, 9, 2407-2497.

36. Shimshoni, J.A.; Cuneah, O.; Sulyok, M.; Krska, R.; Galon, N.; Sharir, B.; Shlosberg, A. Mycotoxins in corn and wheat silage in Israel. Food Addit. Contam. Part A 2013, 30, 1614-1625.

37. Desjardins, A. Fusarium Mycotoxins: Chemistry, Genetics and Biology; APS Press: St. Paul, MN, USA, 2006; pp. 79-108.

38. Mogensen, J.M.; Sørensen, S.M.; Sulyok, M.; van der Westhuizen, L.; Shephard, G.S.; Frisvad, J.C.; Thrane, U.; Krska, R.; Nielsen, K.F. Single kernel analysis of fumonisins and other fungal metabolites in maize from South African subsistence farmers. Food Addit. Contam. Part A 2011, 28, 1724-1734.

39. Axford, L.; Simpson, T.; Willis, C. Synthesis and incorporation of the first polyketide synthase free intermediate in monocerin biosynthesis. Angew. Chem. Int. Ed. 2004, 43, 727-730.

40. $\mathrm{Yu}, \mathrm{J}$. Current understanding on aflatoxin biosynthesis and future perspective in reducing aflatoxin contamination. Toxins 2012, 4, 1024-1057.

41. Versilovskis, A.; de Saeger, S. Sterigmatocystin: Occurrence in foodstuffs and analytical methods-an overview. Mol. Nutr. Food Res. 2010, 54, 136-147.

42. European Food Safety Authority. Scientific Opinion on the risk for public and animal health related to the presence of sterigmatocystin in food and feed. EFSA J. 2013, 11, doi:10.2903/j.efsa.2013.3254.

43. European Parliament. Directive 2002/32/EC of the European Parliament and of the Council of 7 May 2002 on undesirable substances in animal feed. Off. J. L 2002, 140, 10-21.

44. O’Brien, M.; Nielsen, K.F.; O’Kiely, P.; Forristal, P.D.; Fuller, H.T.; Frisvad, J.C. Mycotoxins and other secondary metabolites produced in vitro by Penicillium paneum Frisvad and Penicillium roqueforti Thom isolated from baled grass silage in Ireland. J. Agric. Food Chem. 2006, 54, 9268-9276.

45. Hsu, S-C.; Chung, J.-G. Anticancer potential of emodin. Biomedicine 2012, 2, 108-116.

46. Jizba, J.; Sedmera, P.; Zima, J.; Beran, M.; Blumauerová, M.; Kandybin, N.V.; Samoukina, G.V. Macrotetrolide antibiotics produced by Streptomyces globisporus. Folia Microbiol. 1991, 36, 437-443.

47. Riet-Correa, F.; Rivero, R.; Odriozola, E.; Adrien, M.; Medeiros, R.M.T.; Schild, A.L. Mycotoxicoses of ruminants and horses. J. Vet. Diagn. Investig. 2013, 25, 692-708.

48. Driehuis, F.; Spanjer, M.C.; Scholten, J.M.; Te Giffel, M.C. Occurrence of mycotoxins in maize, grass and wheat silage for dairy cattle in the Netherlands. Food Addit. Contam. Part B Surveill. 2008, 1, 41-50.

49. Reed, K.F.M.; Moore, D.D. A preliminary survey of zearalenone and other mycotoxins in Australian silage and pasture. Anim. Prod. Sci. 2009, 49, 696-703.

50. Skládanka, J.; Nedělník, J.; Adam, V.; Doležal, P.; Moravcová, H.; Dohnal, V. Forage as a primary source of mycotoxins in animal diets. Int. J. Environ. Res. Public Health 2011, 8, 37-50. 
51. Canevari, P.; Blanco, D.E.; Bucher, E.H.; Castro, G.; Davison, I. (Eds.) Los Humedales de la Argentina. Clasificación, situación actual, conservación y legislación; Wetlands International Publication: Buenos Aires, Argentina, 1998; Volume 46, p. 208.

52. Vishwanath, V.; Sulyok, M.; Labuda, R.; Bicker, W.; Krska, R. Simultaneous determination of 186 fungal and bacterial metabolites in indoor matrices by liquid chromatography/tandem mass spectrometry. Anal. Bioanal. Chem. 2009, 395, 1355-1372.

53. European Commission. Commission Decision of 12 August 2002 implementing Council Directive 96/23/EC concerning the performance of analytical methods and the interpretation of results. Off. J. Eur. Union 2002, 29, 10-32.

(C) 2015 by the authors; licensee MDPI, Basel, Switzerland. This article is an open access article distributed under the terms and conditions of the Creative Commons Attribution license (http://creativecommons.org/licenses/by/4.0/). 